\title{
ITINERÁRIOS TERAPÊUTICOS DE MÃES DE CRIANÇAS COM MICROCEFALIA DECORRENTE DA SÍNDROME DO ZIKA VÍRUS
}

\author{
ITINERARIOS TERAPÉUTICOS DE MADRES DE NIÑOS COM MICROCEFALIA \\ TRAS EL SÍNDROME DE ZIKA VIRUS
}

\author{
THERAPEUTIC ITINERARIES OF MOTHERS OF CHILDREN WITH \\ MICROCEPHALY DUE TO ZIKA VIRUS SYNDROME
}

\author{
Andrea Perosa Saigh JURDI ${ }^{1}$ \\ Luísa CHIBANI MAUAD ${ }^{2}$ \\ Mariana FAGUNDES CINTI ${ }^{3}$
}

RESUMO: O objetivo do estudo foi conhecer o itinerário terapêutico de mães de crianças com microcefalia, decorrente da infecção pelo Zika Vírus, nascidas no período de outubro de 2015 a outubro de 2016, moradoras de um município da Região Metropolitana da Baixada Santista. Trata-se de um estudo retrospectivo de abordagem qualitativa que utilizou entrevistas com duas mães que tiveram Zika Vírus confirmado na gestação e cujos filhos nasceram com microcefalia no período da epidemia. Os resultados apontaram que as mães são as cuidadoras principais; as redes de apoio são construídas a partir da família próxima e outras mães de crianças com microcefalia; a religião é acessada quando o saber biomédico não apresenta respostas concretas.

PALAVRAS-CHAVE: Itinerário terapêutico. Microcefalia. Zika vírus.

RESUMEN: El objetivo del estudio fue conocer el itinerario terapéutico de madres de niños con microcefalia provenientes de la infección por el Zika Virus nacidos en el período de octubre de 2015 a octubre de 2016, moradores de un municipio de la Región Metropolitana de la Baixada Santista. Se trata de un estudio retrospectivo de abordaje cualitativo que utilizó entrevistas con dos madres que tuvieron Zika Virus confirmadas en la gestación y cuyos hijos nacieron con microcefalia en el período de la epidemia. Los resultados apuntaron que las madres son las cuidadoras principales; las redes de apoyo se construyen a partir de la familia cercana y otras madres de niños con microcefalia; se accede a la religión cuando el saber biomédico no presenta respuestas concretas.

PALABRAS CLABE: Itinerario terapéutico. Microcefalia. Zika virus

ABSTRACT: The objective of the study was to know the therapeutic itinerary of mothers of children with microcephaly, resulting from the Zika virus infection, born from October 2015 to

\footnotetext{
${ }^{1}$ Universidade Federal de São Paulo (UNIFESP), Baixada Santista, Santos - SP - Brasil. Docente do curso de Terapia Ocupacional. Departamento de Saúde, Educação e Sociedade. ORCID: http://orcid.org/0000-0002-11115562. E-mail: andreajurdi@gmail.com.

${ }^{2}$ Universidade Federal de São Paulo (UNIFESP), Baixada Santista, Santos - SP - Brasil. Discente do curso de Psicologia. ORCID: http://orcid.org/0000-0003-1872-0594. E-mail: lulimauad@ hotmail.com.

${ }^{3}$ Universidade Federal de São Paulo (UNIFESP), Baixada Santista, Santos - SP - Brasil. Discente do curso de Fisioterapia. ORCID: http://orcid.org/0000-0002-1111-5562. E-mail: marianafagundesc@ hotmail.com.
} 
October 2016, living in a Metropolitan Region of Baixada Santista's municipality. This is a retrospective qualitative study that used interviews with two mothers who had Zika virus confirmed during pregnancy and whose children were born with microcephaly, during the epidemic period. The results showed that mothers are the main caregivers; support networks are built from the close family and other mothers of children with microcephaly; religion is accessed when biomedical knowledge does not present concrete answers.

KEY WORDS: Therapeutic itinerary. Microcephaly. Zika virus.

\section{Introdução}

O vírus Zika é considerado um arbovírus que foi isolado pela primeira vez em 1947, em Uganda, e foi identificado no Brasil em 2015. Desde então, sua circulação foi confirmada em 18 estados brasileiros (VARGAS et al., 2016; BRASIL, 2017; PETRÔNIO et al., 2018; FRANÇA et al., 2018).

No Brasil, dados sobre nascidos vivos são registrados a partir da Declaração de Nascido Vivo por ocasião do nascimento e registrados no Sistema de Informações sobre Nascidos Vivos (SINASC) do Ministério da Saúde (MARINHO et al., 2016).

Segundo os autores, no Brasil, no período 2000-2014, o número de nascidos vivos com microcefalia apresentou estabilidade. Porém, a partir de outubro de 2015 houve um aumento inesperado de casos, principalmente na região nordeste do país. Em fevereiro de 2016, o Comitê Internacional de Regulação de Emergências em saúde declarou que o conjunto de casos de microcefalia e outras afecções neurológicas notificadas no Brasil tinham semelhanças com quadros descritos na Polinésia Francesa em 2014, e constituía uma emergência de saúde pública de importância internacional devido à possível associação ao Zika Vírus.

A circulação da doença causada pelo vírus Zika (ZIKV) foi confirmada em fevereiro de 2015, quase simultaneamente na Bahia e em São Paulo e, posteriormente, no Rio Grande do Norte, Alagoas, Maranhão, Pará e Rio de Janeiro, mostrando uma rápida capacidade de dispersão (CAMPOS; BANDEIRA; SARDI, 2015). A partir de abril de 2015, foi confirmada a transmissão autóctone de febre pelo ZIKV no país, bem como foi recomendada a notificação de gestantes com exantema agudo para investigação do ZIKV. Nesse contexto, também foi recomendada a vigilância de microcefalia e/ou alterações do sistema nervoso central (SNC) sugestivas de infecção congênita, para avaliação de recém-nascidos com microcefalia, associadas à infecção pelo ZIKV.

A microcefalia é uma malformação congênita em que o cérebro não se desenvolve de maneira adequada: o perímetro cefálico dos recém-nascidos é menor que dois desvios-padrão 
da média para idade e sexo, podendo levar a alterações cerebrais e problemas no desenvolvimento neurológico (VARGAS et al., 2016).

Há também outra questão que atravessa esta realidade, centrada na complexidade de receber uma criança especial. As famílias, no geral, aguardam ansiosas crianças sadias e eficientes (OLIVEIRA; POLETTO, 2015). O fato é que crianças com necessidades especiais demandam cuidados específicos dos setores de saúde, de educação e social, para além do considerado normal (ASTOLPHO et al., 2014).

Segundo Astolpho et al. (2014), na maioria dos casos em que há a chegada de uma criança especial na família, a mãe se torna a principal cuidadora devido as instruções específicas de cuidados necessários a esse bebê, deixando, por vezes, o seu emprego e diminuindo a renda familiar. Esta rotina causa aumento do estresse e da ansiedade vivenciados pela(o) responsável, além de um isolamento e exclusão social deste indivíduo, que pode acarretar outros prejuízos psíquicos. Portanto, se faz necessária uma rede de cuidado que se estenda para além dos pais, que se encontram sobrecarregados e desamparados, deixando à disposição não apenas profissionais de saúde preparados, como também demais familiares e amigos, ofertando-os o treinamento adequado.

A forma como se é interpretada a deficiência difere entre cada um, de acordo com suas experiências vivenciadas e seu meio de convívio. O mesmo ocorre com a escolha do processo da cura, os significados compartilhados socialmente pela pessoa influenciam nos processos reflexivos e de escolhas pelos sistemas de cuidado à saúde, sendo construído um itinerário terapêutico a partir da experiência da enfermidade vivenciada (SILVA JUNIOR; GONÇALVES; DEMÉTRIO, 2013).

\section{A construção de itinerários terapêuticos}

Cada indivíduo desenvolve maneiras de estar em sociedade, de se relacionar e desenvolver estratégias que lhe permita viver em comunidade e com qualidade. $\mathrm{O}$ nascimento de uma criança com deficiência provoca na família uma desordem, pois os modos rotineiros de lidar com as situações cotidianas e com suas relações sociais tornam-se ineficazes e, muitas vezes, impraticáveis para atender as necessidades da nova situação. Segundo Alves (1993), nesse contexto a família é mobilizada a impor uma certa ordem sobre a experiência perturbadora e transformá-la em algo que possam lidar cotidianamente.

A experiência da enfermidade é o termo utilizado para se referir aos meios pelos quais os indivíduos ou grupos sociais respondem a um episódio de doença e o Itinerário terapêutico 
é o nome dado ao conjunto de planos, estratégias e projetos voltados para resolver o problema - o tratamento da aflição. Para Alves (1993), a construção da imagem acerca de um tratamento é constituída dentro das redes de relações sociais e são justamente essas redes que servem de referência para os indivíduos, sustentando e confirmando as elaborações de imagem de determinados tipos de tratamento.

Dois pontos de partida mobilizaram a pesquisa com mães de crianças com microcefalia decorrentes do Zika vírus: a experiência da enfermidade e a busca que empreenderam ao lidar com algo novo e desconhecido que mobilizou o país inteiro. E, nesse sentido, a preocupação foi em estudar e desvelar o mundo cotidiano, no qual é construído conhecimento a partir da experiência. Para Alves (2015), é no mundo cotidiano que adquirimos um estoque de conhecimento, formado pelo nosso percurso biográfico, pelas circunstâncias que somos enredados e acabamos por desenvolver um conjunto de estratégias e planos de ação para lidar com o mundo da vida.

Portanto, para compreender o IT é necessária uma abordagem que permita estabelecer relações entre a dimensão sociocultural e a conduta singularizada dos indivíduos. O comportamento do enfermo - illness behavior - é permeado por escolhas em prol do custo benefício, pois há a procura daquilo que é preciso para satisfazer suas necessidades. Valores culturais, socioeconômicos, estrutura familiar, gênero, idade e elementos cognitivos são responsáveis e determinantes no processo de escolha do tratamento, designando um itinerário terapêutico singular a cada pessoa (ALVES, 1993).

Este estudo teve por objetivo conhecer os itinerários terapêuticos de mães de crianças com microcefalia decorrentes da SZV, moradoras de um município da Região Metropolitana da Baixa Santista.

\section{Procedimentos Metodológicos}

Trata-se de um estudo retrospectivo de abordagem qualitativa que utilizou entrevistas semiestruturadas para a produção de dados. O critério de inclusão era que a microcefalia fosse decorrente do Zika Vírus e que a criança fosse nascida no período de outubro de 2015 a outubro de 2016. A partir do contato com o setor de Vigilância Epidemiológica do município constatouse sete casos de nascidos vivos com microcefalia no período, mas apenas duas crianças tiveram a confirmação de estar associada à infecção provocada pelo vírus Zika durante a gestação.

As duas mães foram contatadas por ligação telefônica e ambas aceitaram participar do estudo. Ocorreu um encontro, com cerca de uma hora de duração, com cada mãe no local em 
que elas desejassem e durante este momento foram realizadas as entrevistas e a aplicação de um questionário sociodemográfico. As entrevistas ocorreram no período de fevereiro a abril de 2018, pois dependeram da disponibilidade das participantes da pesquisa. Em ambos os encontros, as entrevistas foram gravadas em dois aparelhos diferentes, um gravador e um celular, tudo com o consentimento das participantes que tiveram as identidades preservadas.

Para homologar o consentimento, as voluntárias receberam o Termo de Consentimento Livre e Esclarecido, podendo ler o documento e assiná-lo, a fim de tomar conhecimento dos princípios éticos do estudo, que foi submetido à avaliação e aprovado pelo Comitê de Ética e Pesquisa com Seres Humanos da Universidade conforme a Resolução nº 466/2013, do Conselho Nacional de Saúde, sob o parecer de número 2.317.477, validando sua participação e a utilização dos dados por elas informados.

O processo de análise dados se deu a partir da técnica de análise temática proposta por Minayo (2014). Tal escolha se deu a partir do pressuposto que os valores de referência e os modelos de comportamento, observados no discurso, são caracterizados pela presença de determinados temas nos quais se busca a explicitação dos sentidos contidos nas falas, documentos ou fenômenos e os significados. $\mathrm{O}$ material produzido foi reunido e os temas identificados como relevantes foram agrupados em categorias elaboradas a partir do objetivo do estudo, descritas na apresentação dos resultados.

\section{Cenário da pesquisa}

Um estudo sobre itinerários terapêuticos obrigatoriamente nos leva a conhecer o contexto em que se encontram as estratégias, os planos de ação que os indivíduos desenvolvem em busca de cuidados com a saúde. As ofertas e o acesso aos serviços, os recursos existentes precisam ser compreendidos e conhecidos.

O município de moradia das famílias é a cidade polo da Região Metropolitana da Baixada Santista com cerca de 421.896 habitantes, sendo que cerca de 30,5\% apresentam algum tipo de deficiência (IBGE, 2010). Apesar de ocupar a terceira posição no Índice de Desenvolvimento Humano (IDH) no Estado de São Paulo, o município ainda assim possui regiões com altos índices de vulnerabilidade. Essas regiões receberam um fluxo migratório muito intenso nas últimas décadas, o que ocasionou na ocupação do território, com sérios problemas nas condições de vida e na infraestrutura local.

Em relação aos serviços de saúde, estes têm uma abrangência nos três níveis de atenção em todo o município. Em 2016 foi instituída a Rede de Cuidados a Pessoa com Deficiência que 
contou com a construção de um Centro Especializado de Reabilitação (CER). Paralelo aos serviços públicos de saúde, educação e assistência social, o município conta com um número considerável de instituições filantrópicas especializadas que atendem crianças, jovens e adultos com deficiências, desde a intervenção precoce até a inclusão no mercado de trabalho.

\section{Resultados e Discussão}

Será feita uma breve apresentação das participantes da pesquisa e uma análise das falas a partir de três categorias que emergiram das entrevistas articuladas ao contexto nacional, municipal e aos autores que dialogam com o tema. As categorias discutidas serão: momento do diagnóstico, busca por tratamento, rede social - subsistemas familiar e popular. Os nomes são fictícios a fim de manter o sigilo das participantes.

Vanessa é mãe de Clara que nasceu em 03/11/2015. Além de Clara, tem mais dois filhos adolescentes, um rapaz de 16 anos e uma garota de 14 anos. Todos moram na mesma casa no bairro Rádio Clube, localizado na Zona Noroeste do município de Santos. Essa região é conhecida pela alta vulnerabilidade social e possui infraestrutura precária. É uma região de palafitas, apesar de não ser o caso da participante da pesquisa. Atualmente, Vanessa depende financeiramente de uma pensão do pai de Clara e não trabalha. Deixou o emprego durante a gestação, quando começou o acompanhamento no Hospital das Clínicas, em São Paulo.

Joice é mãe de Letícia que nasceu em 17/11/2015, mora na região do Macuco em Santos e recebeu o diagnóstico de filha com sete meses de gestação. Estava grávida de gêmeos, a menina nasceu com a microcefalia e o menino não. Descobriu que foi por causa da Síndrome do Zika Vírus depois de participar de um estudo para uma universidade, pois no momento em que teve a febre, pensou ser dengue. Tem mais dois filhos, além dos gêmeos, e mora com seu marido, que é gesseiro.

\section{Momento do diagnóstico}

Para as participantes esse momento se deu em tempos diferentes da gestação. Joice retrata a dificuldade que teve em compreender a notícia e falta de apoio que teve por parte da equipe médica com a qual realizava o pré-natal.

Foi com trinta e quatro semanas mais ou menos já, eles não sabiam o que era ao certo, né, aí passava por uma médica achava que era uma coisa, aí outra médica achou que era outra, aí de repente eles jogaram na minha cara assim, demoraram, demoraram pra falar né, ai de repente eles: "ó, o crânio do bebê 
não..", eles falaram: "o crânio do bebê não tá crescendo. O crânio de um dos bebês, que é o da menina [...]”" (Joice).

Para Vanessa o diagnóstico de microcefalia foi dado durante a gestação, mas foi associado à SZV posteriormente.

Na gestação eu já tinha descoberto que ela ia nascer com microcefalia. Mas eu tive a Zika, vários sintomas. Dos quatro meses em diante, até o terceiro mês ela era normal, a Clara não tinha nada. Depois que eu fiquei gripada e apareceu, foi aparecendo as intercorrências, ela teve, eu fiz a amostra lógica, aí apareceu lâmina discreta de derrame pericárdico (Vanessa).

Em relação ao desconhecimento sobre a microcefalia, Vanessa diz que em um primeiro momento não sabia sobre a microcefalia e foi procurar na internet informações a respeito do assunto.

Ai foi assim, eu falei "mas o que é isso doutor?", ai ele falou "é uma doença que a cabeça não cresce do tamanho certo, não que a cabeça não vá crescer, mas não vai crescer igual nossa", [...] Na verdade eu perguntei, mas depois fiquei procurando na famosa internet, mas é uma coisa que internet hoje não divulgo pra nenhuma mãe, por que ela te dá positividade e negatividade. Então ela te mostra mais o negativo que o positivo. [Eu via] que ela ia nascer sem cabeça. Aí eu falei "doutor não vai ter nem cabeça, o senhor ta mentindo", dai ele me mostrou "olha, tem cabeça, mas não é aquilo" (Vanessa).

O desconhecimento acerca da microcefalia também faz parte da fala de Joice.

Como é que vai ser quando nascer? Qual vai ser a feição dela, se as pessoas iam rir dela quando a gente andasse na rua. Aí eu dizia: 'Ai meu Deus, eu vou ter que cobrir a cabeça dela, eu vou ter que cobrir a cabeça'. [...], mas depois que nasceu, aí relevei de boa, nunca cobri a cabeça dela (Joice).

As mães obtiveram o diagnóstico no auge da epidemia e, coincidentemente, com o evento das Olimpíadas no Brasil, ganhando repercussão internacional (TRILLA, 2018). Segundo o MS, o primeiro sinal de que o vírus Zika não era tão inofensivo quanto se assegurava foi quando o diretor de Doenças Transmissíveis do MS revelou que o número de casos da Síndrome Guillian-Barré estava acima do padrão e havia a suspeita de ligação com o vírus. Concomitante a isso, em Pernambuco aumentava o número de casos notificados de microcefalia, levantando a hipótese de que o fenômeno estava associado ao vírus (BRASIL, 2017). No município da pesquisa aumentaram as notificações de nascidos vivos com microcefalia no período, mas por Zika vírus apenas dois foram confirmados.

O momento inicial da notícia sobre a deficiência de um filho e o apoio que as famílias necessitam nesse momento é o que as levará e direcionará a busca por cuidados a seus filhos. 
Para Astolpho et al. (2014), a extensa e pesada demanda por cuidados leva a família a se reorganizar e se faz necessário uma rede de cuidado que se estenda para além dos pais, deixando à disposição não apenas profissionais de saúde preparados, como também demais familiares e amigos. Segundo Barbosa et al. (2009), as relações estabelecidas e reorganizadas após a vinda de uma criança com deficiência se configuram desde o momento que a família recebe o diagnóstico, podendo ser determinante, inclusive, na forma como este bebê é visto e recebido.

A busca das mães, por tentarem entender sobre a microcefalia, envolveu aspectos sociais, cognitivos, subjetivos (individuais) e objetivos (coletivos), que Alves (1993) destaca que fazem parte da experiência da enfermidade. Para o autor, a questão chave é como tornar inteligível o movimento pelo qual as práxis individuais e a generalidade social se constituem entre si. É preciso compreender as dimensões cognitivas e sociais incorporadas nas representações individuais. Ambas as mães foram em busca de saber o que era a microcefalia e porque estava acometendo seu filho.

\section{A busca por tratamento}

Diferente das famílias de crianças nascidas com microcefalia provocadas pelo SZV no Nordeste, que sofreram com a falta de serviços acessíveis, de informação e apoio institucional, as mães entrevistadas traçaram outro percurso na busca pelo cuidado de suas crianças. Segundo o MS, as lacunas no conhecimento, os desafios para assistência às crianças e suas famílias - a maior parte oriunda de famílias de classe econômica menos privilegiada, de mães com pouca escolaridade - ainda é um desafio. O documento do MS ressalta que apesar da competência profissional, tornou-se evidente as dificuldades de acesso à saúde, revelando a ausência do Estado e tornando essas mulheres e crianças ainda mais expostas ao potencial agressivo de um vírus (BRASIL, 2017).

Para Freitas et al. (2018), a nova epidemia já desenhava sua determinação social ligada à pobreza, péssimas condições de habitação, ausência de planejamento e desenvolvimento da urbanização e saneamento básico inexistente, transformando o cuidado às crianças em uma tarefa complexa e extenuante. No município da pesquisa, apenas uma mãe mora em uma área de vulnerabilidade e com pouca infraestrutura, mas mesmo esta conseguiu recursos para o tratamento da filha.

Para Vanessa, o cuidado médico e acompanhamento de sua filha, além da pesquisa sobre as causas da microcefalia de Clara são feitos pelo Hospital das Clínicas em São Paulo desde a 
gestação. Os profissionais de lá a acompanham regularmente e a encaminharam para o processo de reabilitação de Clara na instituição especializada no município de Santos.

Ela [a criança] passa no neuro, fono, endócrino, urologista, pediatra, nutrologia, tudo lá. Genética e infectologista. [Vai] Todo mês. A iniciativa do tratamento terapêutico, de fono, de psicólogo, todo, foi deles, do Hospital das Clínicas. Que, como ela tem a micro, eles são uns bebês muito rígidos, eles indicaram fazer a terapia. Foi o Hospital das Clínicas mesmo, os médicos mesmo. [Há] 2 anos e uns quebrados. 2 anos e quatro meses, por que ela entrou tinha um mês (Vanessa).

Para Meneses et al. (2017), os usuários dos serviços de saúde constroem verdadeiros mapas de cuidado a partir de conhecimento prático, fazendo uso do aparato médico-hospitalarambulatorial, a depender de seus recursos. Para Vanessa, o fato de conseguir o atendimento em um grande hospital, facilita o cuidado de Clara em muitos aspectos.

Porque a gente sabe que você vai além. Eu vou mesmo, porque eu vou falar um negócio, eu não paro com a Clara. De segunda a segunda eu vou, vou pra São Paulo. É que na verdade assim, a Unidade Básica de Saúde eu até passo... Então todo mês eu tenho consulta de rotina. [...] Como eu falei [...] "Olha, exames que elas [outras mães] estão procurando pra fazer, tentando, eu já fiz, já vou até refazer". É bem difícil aqui, exames como tomografia é demorado. Se você não tem plano de saúde é demorado aqui. Um que é bastante assim, que elas procuram bastante, vídeo de mielograma com imagem (Vanessa).

Para Joice, a busca por tratamento partiu de iniciativa própria e se configurou como um itinerário mais complexo. Letícia nasceu em uma maternidade pública do município e foi encaminhada ao neurologista.

Encaminharam só pro neuro, só que o neuro tava de férias. Aí eu fui na prefeitura, passei no pediatra, o pediatra da prefeitura me encaminhou pra doutora lá na zona noroeste, lá na zona noroeste ela me deu uma cartinha e eu levei pra Casa da Esperança. Foi assim. Ela faz fono, fisio, é, estimulação precoce, aí ela é acompanhada pelo... uma... esqueci o nome, terapeuta ocupacional, fisioterapia, fono, aí ela passa no ortopedista, passa na neuro, que é na Casa X, tudo é lá, tem dentista. Só o pediatra que eu passo na policlínica, mas o resto eu passo tudo lá ela, ela tem assim, um acompanhamento bacana que é num lugar só, você tem a médica que cuida lá das crianças (Joice).

Para além dos atendimentos de reabilitação e especialidades médicas, ambas as mães relatam a necessidade de um atendimento psicológico, principalmente no início quando a notícia sobre a microcefalia é dada à família.

O processo de reabilitação e atendimentos médicos é constante e se estende por longos períodos, principalmente em função das condições clínicas e comprometimento das crianças. 
Vanessa refere que a filha tem comorbidades associadas como epilepsia e Síndrome de West, o que agrava o quadro clínico da criança. Para Vargas et al. (2016), a microcefalia não configura uma doença e sim uma malformação congênita, sendo assim, os cuidados são constantes e se iniciam a partir do momento em que o bebê nasce, concomitantemente com a orientação médica, que acompanha o desenvolvimento do bebê desde o pré-natal.

De acordo com o depoimento das mães, o cuidado médico está, desde o nascimento, muito presente na rotina da família, tendo forte influência sobre as ações tomadas diante de qualquer problema. A percepção de que, neste caso, o subsistema profissional é o mais acatado fica evidente. A dominância deste modelo em nossa sociedade se dá, no geral, pois o campo das deficiências está sob o domínio dos especialistas médicos.

É preciso salientar que o município, desde 2016, elaborou a Rede de Cuidados à Pessoa com Deficiência (RCPD). Apresentada no bojo do Plano Viver sem Limites, a RCPD se apresenta como uma política estruturante do SUS, incluindo todas as áreas de atenção, desde atenção básica a urgência e emergência, atenção hospitalar e especializada, com o fortalecimento da articulação entre os níveis e modalidades de atenção à saúde, buscando a integralidade e a equidade como pressupostos para seu planejamento e gestão. Hoje o município conta com um Centro Especializado de Reabilitação (CER II) que atende pessoas com deficiência intelectual e Transtorno do Espectro Autista. Além disso, há um número significativo de entidades filantrópicas conveniadas com as secretarias municipais que oferecem atendimento especializado às pessoas com deficiência e realizam o processo de reabilitação e de intervenção precoce.

\section{Rede Social e os subsistemas familiar e popular}

Em momentos da entrevista foi perguntado a Vanessa e Joice se elas buscaram algum outro tipo de cuidado, para além do cuidado considerado formal, e em que situações elas encontraram apoio para lidar com as dificuldades e tensões.

Com relação à rede de apoio, Vanessa e Joice contam ter enfrentado e ainda enfrentar o afastamento das pessoas de seu convívio após os diagnósticos. Apresentam em seus relatos o apoio familiar representado apenas pela figura de familiares próximos. Quando perguntado a Joice sobre suas amizades e laços sociais, ela fala apenas das demais mães que, assim como ela, são "mães especiais" por terem filhos com microcefalia ou dos profissionais que oferecem acolhimento e auxiliam em outras questões do desenvolvimento da Letícia. Ela faz referência 
a essas mães como suas únicas amigas, pois são capazes de compreender o que ela passa em seus desafios cotidianos.

Tive uma amiga mesmo minha, ela é minha ex cunhada, tia dos meus dois mais velhos, não tem nada a ver com a Clara. Hoje em dia ela fala que a Clara é a sobrinha dela também. E ela me deu muita força porque ela que mora lá em São Paulo, ela que me ajudou a ir, acompanhou, porque o pai da Clara trabalhava e a gente não estava junto, o pai dela trabalhava, alguém tinha que trabalhar né (Vanessa).

Para Joice a rede apoio se refere à família nuclear e às mães da instituição que frequenta.

Já apanhei tanto na vida que quando eu tive ela, no momento que eu tive ela, eu fiquei sozinha, não tinha ninguém. Ninguém sente sua dor, ninguém tem compaixão de você. Então se você não tiver forças, fé e coragem, você vai ficar ali triste, com depressão, desanimado e as pessoas vão passar por você vão rir de você.[...] Que nem eu quando vou na Casa X, quando eu encontro as mães, eu me sinto tão bem que eu digo "eu senti até saudades de vocês", eu sinto até falta. Minhas amigas agora são elas, porque o assunto da gente é o mesmo, bate. [...] Como que a gente aprende, eles ensinam a gente a cuidar deles. Já tem gente que diz "eu não dou mamadeira por que engasga", "ah, eu não dou isso por que engasga" (Joice).

Além da família, Joice fala sobre o apoio formal de profissionais da saúde

Psicólogo é ótimo, não vou mentir, precisa conversar com psicólogo, amigos, mas a parte da psicologia é muito bom, foi bem efetiva. A equipe médica que fez o meu pré-natal, eles me acolheram, me confortavam, conversavam comigo, nunca falavam uma palavra que fosse negativa, mas também nunca escondiam, eles falavam tudo, então acho que foi o que me deixou bem mais tranquila (Joice).

Em um episódio em que Clara ficou doente, Vanessa refere que a religião a ajudou a enfrentar a situação.

Ele falou bem na minha cara: "com os exames dela alterado como tá aqui, ela não vai aguentar”. Então a gente apela pra onde? Pra fé, né. Então eu orei de um lado, liguei pra minha mãe, falei: "olha mãe, reza a senhora aí, eu vou orar, porque a minha religião é cristã, eu sou cristã, então a senhora aí na sua reza pra Nossa Senhora da Aparecida, Nossa Senhora de Fátima, depois eu pago tudinho [risos] (Vanessa).

Em relação às crenças e o saber popular, Joice diz que foi criada na igreja evangélica, mas quando sente necessidade transita por outras religiões.

Que nem agora no Nordeste, ela, do nada, ficou toda vermelha, ai levei ela a casa de uma "rezadeira", ai ela rezou, ela ficou boa. [...] Acredito, assim, antes eu não acreditava na reza né? Depois que eu comecei a acreditar, por que evangélica com reza não bate muito né? É mais na oração. Mas eu acho que é uma coisa, tipo assim, é o mesmo Deus, pedindo o que é bom. Então eu 
tento, procurava as orações quando ela ficava, lógico que eu dava o remédio né, também [risos]. Lógico que eu dava o remédio, mas orava bastante, cantava pra e lá e tal (Joice).

Na extenuante trajetória por estratégias de enfrentamento, as famílias vão adquirindo a tarefa de encontrar caminhos e possibilidades diversas para lidar com as adversidades e limitações com as quais se deparam. A relação social, familiar e até mesmo conjugal é muitas vezes afetada em função de um cotidiano repleto de desafios. A vida social das mães responsáveis por crianças com deficiência, por vezes, é reprimida, fazendo com que estas mulheres se sintam isoladas, sozinhas e impedidas de viverem experiências além do cuidado aos seus bebês. O contato com outras mães da instituição favorece a troca de saberes e experiências, fortalecendo a perspectiva de que outras pessoas também passam por situações similares, e fazendo com que elas integrem um grupo social e de apoio, além de diminuir angústias e aflições que as fazem sentir-se desamparadas (BARBOSA et al., 2009).

\section{Considerações finais}

O cuidado de crianças com microcefalia decorrente da Síndrome do Zika Vírus ainda é muito vinculado ao saber médico e dos demais profissionais de saúde, devido à deficiência ser detectada desde a gravidez, estreitando estas relações de cuidado. A procura pelas demais formas de atenção à saúde, inseridas nos subsistemas popular e familiar, fica condicionada ao contexto sociocultural em que os indivíduos estão inseridos.

O cotidiano das famílias e as relações que nela se estabelecem também sofrem alterações com a chegada de um bebê com deficiência, acometendo principalmente as mães que, na maioria das vezes, se encarregam da responsabilidade de criação de seus filhos. As consequências desta dedicação exclusiva são exaustivas para as mulheres que ocupam esta função, além das sobrecargas emocional, social e financeira que acometem suas realidades e da quebra de expectativas que receber uma criança com deficiência representa para a família (BARBOSA et al., 2009).

No estudo foi possível identificar que a enfermidade não é apenas um estado de fragilidade e sofrimento, como também uma realidade social. Nesta perspectiva, o sistema leigo de referência, que segundo Alves (1993) se configura em premissas que diferem do sistema biomédico, tem a função de dar conta das diversas definições de doença, buscando contextualizar os indivíduos na sua totalidade. 
AGRADECIMENTOS: A Fundação de Amparo à Pesquisa do Estado de São Paulo (FAPESP) pelo financiamento desta pesquisa durante o período de 12 meses.

\section{REFERÊNCIAS}

ALVES, P. C. A Experiência da Enfermidade: Considerações Teóricas. Cad. Saúde Públ., Rio de Janeiro, v. 9, n. 3, p. 263-271, 1993.

ALVES, P.C. Itinerário Terapêutico e os Nexus de Significados da Doença. Ver. Política \& Trabalho, n. 42, p. 29-43, jan./jun. 2015. Disponível em:

http://periodicos.ufpb.br/ojs/index.php/politicaetrabalho/issue/view/1659/showToc. Acesso em: 4 set 2018.

ASTOLPHO, M. P. et al. Rede de cuidados a crianças com necessidades especiais de saúde. Rev. bras. enferm., Brasília, v. 67, n. 2, p. 213-219, abr. 2014.

BARBOSA, M. A. M. et al. Cuidado da Criança com Deficiência: suporte social acessado pelas mães. Rev. Gaúcha Enferm, Porto Alegre, v. 30, n. 3, p. 406-412, set. 2009.

BRASIL. Ministério da Saúde. Secretaria de Vigilância em Saúde. Vírus Zika no Brasil: a resposta do SUS [recurso eletrônico]. Ministério da Saúde, Secretaria de Vigilância em Saúde. - Brasília: Ministério da Saúde, 2017. Disponível em:

http://bvsms.saude.gov.br/bvs/publicacoes/virus_zika_brasil_resposta_sus.pdf. Acesso em: 20 nov. 2019.

CAMPOS, G. S.; BANDEIRA, A. C.; SARDI, S. I. Zika virus outbreak, Bahia, Brazil.

Emerging Infectious Diseases. v. 21, n. 10, p. 5, Oct. 2015. Disponível em:

https://wwwnc.cdc.gov/eid/article/21/10/15-0847_article. Acesso em: 20 nov. 2019. DOI:

https://doi.org/10.3201/eid2110.150847.

FRANÇA, G.V. A. et al. Síndrome Congênita associada à infecção pelo vírus Zika em nascidos vivos no Brasil: descrição da distribuição dos casos notificados e confirmados em 2015-2016. Epideomiol Serv Saúde, Brasília, v. 27, n. 2, 2018.

IBGE - Instituto Brasileiro de Geografia e Estatística. Censo demográfico 2010.

Características gerais da população, religião e pessoas com deficiência. Rio de Janeiro: IBGE, 2012. Disponível em:

ftp://ftp.ibge.gov.br/Censos/Censo_Demografico_2010/Caracteristicas_Gerais_Religiao_Defi ciencia/caracteristicas_religiao_deficiencia.pdf. Acesso em: 7 set 2018.

MARINHO, F. et al. Microcefalia no Brasil: prevalência e caracterização dos casos a partir do Sistema de Informações sobre Nascidos Vivos (Sinasc), 2000-2015. Epidemiol. Serv. Saúde, Brasília, v. 25, n. 4, p. 701-712, dez. 2016.

MENESES, C.S. et al. O Agir leigo e a Produção de Mapas de Cuidado Mistos PúblicoPrivados. Ciência \& Saúde Coletiva, v. 22, n. 6, p. 2013-2017, 2017. 
MINAYO, M. C. S. O desafio do conhecimento: pesquisa qualitativa em saúde. São Paulo: Hucitec, 14 ed., 2014.

OLIVEIRA, I. G. de; POLETTO, M. Vivências emocionais de mães e pais de filhos com deficiência. Rev. SPAGESP, Ribeirão Preto, v. 16, n. 2, p. 102-119, 2015.

PETRÔNIO, C. N. V. et al. O Início da epidemia do Zika Vírus e os seus Reflexos na Saúde Pública Nacional e Internacional. Id On Line - Ver. Mult. Psi., v. 12, n. 40, 2018.

SILVA JUNIOR, N. D.; GONÇALVES, G.; DEMÉTRIO, F. Escolha do itinerário terapêutico diante dos problemas de saúde: considerações socioantropológicas. Revista Eletrônica Discente História, v. 1, n. 1, p. 1-12, 2013.

TRILLA, A. Zika y médios de comunicacion: 213 gana a 170. Enfermedades Emergentes Revista Multidisciplinar sobre enfermedades nuevas, emergentes, re-emergentes o de impacto para la salud publica global, v. 17, n. 1, p. 3-6, 2018.

VARGAS, A. et al. Características dos primeiros casos de microcefalia possivelmente relacionados ao vírus Zika notificados na Região Metropolitana de Recife, Pernambuco. Epidemiol Serv Saúde. v. 25, n. 4, p. 691-700, out. 2016.

\section{Como referenciar este artigo}

JURDI, Andrea Perosa Saigh; CHIBANI MAUAD, Luísa, FAGUNDES CINTI, Mariana. Itinerários terapêuticos de mães de crianças com microcefalia decorrente da síndrome do Zika vírus. Temas em Educ. e Saúde, Araraquara, v. 15, n. 2, p. 263-276, jul./dez. 2019. e-ISSN 2526-3471. DOI: https://doi.org/10.26673/tes.v15i2.13078

Submetido em: 20/02/2019

Revisões requeridas: 05/04/2019

Aprovado em: 30/05/2019

Publicado em: 30/07/2019 